\title{
Drug-facilitated sexual assault
}

\section{Introduction}

The term "date rape" is misleading because it implies that there is a relationship between the victim and the offender.

By using the term "acquaintance rape" in place of "date rape," we are making that distinction. ${ }^{1}$

a. The vast majority of sexual assault offenders are known to their victims, but they are not necessarily in a dating relationship.

b. It really should not have to be stated that agreeing to go out on a date with someone does not provide consent to sex. ${ }^{2}$

c. Drug-facilitated sexual assault occurs when an offender either intentionally administers drugs or alcohol to a potential victim to facilitate an assault or takes advantage of the victim's intoxicated state to force sexual contact.Also, not all sexual assaults involve the use of alcohol/drugs. ${ }^{3}$

d. It is more appropriate to call these crimes "drug-facilitated sexual assaults". ${ }^{4}$

\section{Body}

At least, twenty drugs have been used for drug-facilitated sexual assault (DFSA). The commonly known as date-rape drugs, including gamma-hydroxy-butyrate (GHB), flunitrazepam, ketamine, zolpidem are the most common DFSA. ${ }^{4}$

Gamma hydroxy butyrate is a naturally-occurring metabolite of the inhibitory neurotransmitter gamma aminobutyric acid (GABA). Itis originally developed as an anesthetic in 1960. GHB is also used in body building. It has been illegally used as a date rape drug due to its strong side effect of loss of motor power and/or amnesia that may occur. ${ }^{5,6}$

Flunitrazepam is an intermediate-acting benzodiazepine. Its sedative effects are 7 to 10 times stronger than Diazepam. It is commonly referred to as a date rape drug due to the loss of motor control, lack as coordination and strong amnesia. ${ }^{7}$

Ketamine is a dissociative general anesthetic that has been available since 1970 . It is related to phencyclidine, but has less than $10 \%$ of the potency of pure phencyclidine.It is an animal tranquilizer. It has become popular as a date rape drug due to its side effect as confusion and/or amnesia. ${ }^{8}$

Zolpidem is a short acting non-benzodiazepine hypnotic of the imidazopyridine classthat potentiates GABA, by binding to GABA receptors at the same location as benzodiazepines. It is used for the treatment of insomnia and some brain disorders. More recently, zolpidem has become a leading date rape drug due to its side effects as lack of coordination and amnesia.?

Alcohol usually facilitates rape as:

a. It reduces judgment, reasoning, physical ability to resist assaults.

b. It contributes to lack of common sense.

c. It triggers aggressive behavior.
Volume 2 Issue I - 2016

\author{
Usama Mohamed El-Barrany \\ Department of Forensic Medicine \& Clinical Toxicology, Cairo \\ University, Egypt
}

Correspondence: Usama Mohamed El-Barrany, Department of Forensic Medicine \& Clinical Toxicology, Cairo University, Egypt, Tel +20 I I 4409 I I I6,

Received: January 30, 2016 | Published: February II, 2016

d. It leads to feeling of invincibility.

e. It is often mixed with date rape drugs ${ }^{10}$

f. It is difficult to statistically document because many don't report.

g. Shame and possible fear of being blamed for what happened.

h. Concern about criminal charges for underage drinking or illegal drug use.

i. Drugs metabolize quickly, hard to detect; and clinical detection may be difficult after an assault. ${ }^{11}$

Investigations of DFSA include case history information, laboratory analysis, case consultation and interpretation of findings. For laboratory detection of date-rape drugs in urine, blood and/or hair, immunoassay and/or gas chromatography-mass spectrum (GC-MS) may be used. ${ }^{12,13}$

\section{Conclusion and recommendations}

To reduce the risk, there should be international laws to avoid or at least to regulate selling and buying such drugs at gymnasiums, bars, discos, and rave clubs, as well as over the Internet. Non-using is the safest. Mixing with drugs especially alcohol increases risk for harm. Use with trusted others.If you accept a drink; make sure it's from an unopened container. Be aware of any strange taste or color in your drink. If you think that you have been a victim, notify authorities. If you think you could have been poisoned, seek help immediately. ${ }^{14}$

\section{Acknowledgements}

None.

\section{Conflict of interest}

The author declares no conflict of interest.

\section{References}

1. Fendrich M, Wislar JS, Johnson TP, et al. A contextual profile of club drug use among adults in Chicago. Addiction. 2003;98(12):1693-1703.

2. Mohler-Kuo M, Dowdall GW, Koss MP, et al. Correlates of rape while intoxicated in a national sample of college women. Journal of Studies on Alcohol. 2004;65(1):37-45.

3. Cybulska B. Sexual assault: key issues. Soc Med. 2007;100(7):321-324. 
4. Mont JD, Macdonald S, Rotbard N, et al. Factors associated with suspected drug-facilitated sexual assault. CMAJ. 2009;180(5):513-519.

5. Dargan PI, Button J, Davies S, et al. The first reported UK fatality related to gamma-butyrolactone (GBL) ingestion. $J R$ Soc Med. 2009;102(12):546-547.

6. Kavanagh PV, Kenny P, Feely J. The urinary excretion of gammahydroxy butyric acid in man. Journal of Pharmacy \& Pharmacology. 2001;53(3):399-402.

7. Walshe K, Barrett AM, Kavanagh PV, et al. A sensitive immunoassayfor flunitrazepam and metabolites. Journal of Analytical Toxicology. 2000;24(4):296-299.

8. Li JH, Vicknasingam B, Cheung YW, et al. To use or not to use: an update on licit and illicit ketamine use. Subst Abuse Rehabil. 2011;2:1120 .

9. Berdyyeva T, Otte S, Aluisio A, et al. Zolpidem Reduces Hippocampal Neuronal Activity in Freely Behaving Mice: A Large Scale Calcium Imaging Study with Miniaturized Fluorescence Microscope. PLoS One. 2014;9(11):e112068.
10. Abbey A, Zawacki T, Buck PO, et al. Alcohol and sexual assault. Alcohol Research \& Health: the Journal of the National Institute on Alcohol Abuse \& Alcoholism. 2001;25(1):43-51.

11. Wahab S, Olson L. Intimate Partner Violence and Sexual Assault in Native American Communities. Trauma, Violence \& Abuse. 2004;5(4):353-366.

12. Hindmarch I, ElSohly MA, Gambles J, et al. Forensic urinalysis of drug use in cases of sexual assault. Journal of Clinical Forensic Medicine. 2001;8(4):197-205

13. Oiestad EL, Johansen U, Oiestad AM, et al. Drug screening of whole blood by ultra-performance liquid chromatography-tandem mass spectrometry. J Anal Toxicol. 2011;35(5):280-293.

14. Littleton HL, Grills-Taquechel AE, Buck KS, et al. Health RiskBehavior and Sexual Assault Among Ethnically Diverse Women. Psychol Women Q. 2013;37(1):7-21. 